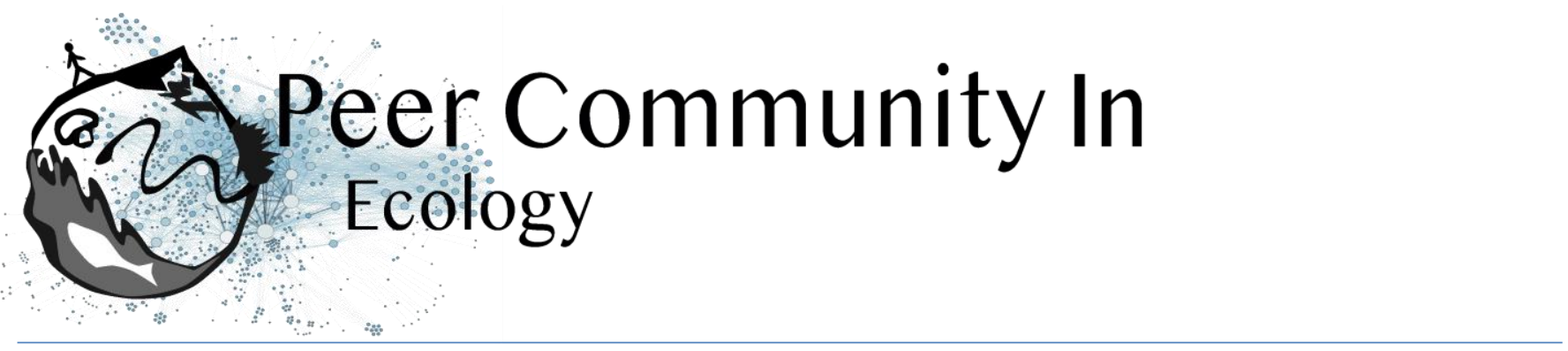

\title{
A planned experiment on local adaptation in a host-parasite system: is adaptation to the host linked to its recent domestication?
}

Eric Petit based on reviews by Alex Stemmelen, Sharon Zytynska and 1 anonymous reviewer

\section{A recommendation of:}

Experimental test for local adaptation of the rosy apple aphid (Dysaphis plantaginea) during its recent rapid colonization on its cultivated apple host (Malus domestica) in Europe

\section{Open Access}

Olvera-Vazquez S.G., Alhmedi A., Miñarro M., Shykoff J. A., Marchadier E., Rousselet A., Remoué C., Gardet R., Degrave A. , Robert P. , Chen X., Porcher J., Giraud T., VanderMijnsbrugge K., Raffoux X., Falque M., Alins, G., Didelot F., Beliën T., Dapena E., Lemarquand A. and Cornille A.(2021), GitLab, ver. 4 https://forgemia.inra.fr/amandine.cornille/local_adaptation_dp

Published: 26 April 2021

Copyright: This work is licensed under the Creative Commons Attribution-NoDerivatives 4.0 International License. To view a copy of this license, visit http://creativecommons.org/licen ses/by-nd/4.0/
Submitted: 26 July 2020, Recommended: 20 April 2021

\section{Recommendation}

Local adaptation shall occur whenever selective pressures vary across space and overwhelm the effects of gene flow and local extinctions (Kawecki and Ebert 2004). Because the intimate interaction that characterizes their relationship exerts a strong selective pressure on both partners, host-parasite systems represent a classical example in which local adaptation is expected from rapidly evolving parasites adapting to more evolutionary constrained hosts (Kaltz and Shykoff 1998). Such systems indeed represent a large proportion of the study-cases in local adaptation research (Runquist et al. 2020). Biotic interactions intervene in many environment-related societal challenges, so that understanding when and how local adaptation arises is important not only for understanding evolutionary dynamics but also for more applied questions such as the control of agricultural pests, biological invasions, or pathogens (Parker and Gilbert 2004).

The exact conditions under which local adaptation does occur and can be detected is however still the focus of many theoretical, methodological and empirical studies (Blanquart et al. 2013, Hargreaves et al. 2020, Hoeksema and Forde 2008, Nuismer and Gandon 2008, Richardson et al. 2014). A recent review that evaluates investigations that examined the combined influence of biotic and abiotic factors on local adaptation reaches partial conclusions about their relative importance in different contexts and underlines the many traps that one has to avoid in such studies (Runquist et al. 2020). The authors of this review emphasize that one should evaluate local adaptation using wild-collected strains or populations and over multiple generations, on environmental gradients that span natural ranges of variation for both biotic and abiotic factors, in a 
theory-based hypothetico-deductive framework that helps interpret the outcome of experiments. These multiple targets are not easy to reach in each local adaptation experiment given the diversity of systems in which local adaptation may occur. Improving research practices may also help better understand when and where local adaptation does occur by adding controls over p-hacking, HARKing or publication bias, which is best achieved when hypotheses, date collection and analytical procedures are known before the research begins (Chambers et al. 2014). In this regard, the route taken by Olvera-Vazquez et al. (2021) is interesting. They propose to investigate whether the rosy aphid (Dysaphis plantaginea) recently adapted to its cultivated host, the apple tree (Malus domestica), and chose to pre-register their hypotheses and planned experiments on PCl Ecology (Peer Community In 2020). Though not fulfilling all criteria mentioned by Runquist et al. (2020), they clearly state five hypotheses that all relate to the local adaptation of this agricultural pest to an economically important fruit tree, and describe in details a powerful, randomized experiment, including how data will be collected and analyzed. The experimental set-up includes comparisons between three sites located along a temperature transect that also differ in local edaphic and biotic factors, and contrasts wild and domesticated apple trees that originate from the three sites and were both planted in the local, sympatric site, and transplanted to allopatric sites. Beyond enhancing our knowledge on local adaptation, this experiment will also test the general hypothesis that the rosy aphid recently adapted to Malus sp. after its domestication, a question that population genetic analyses was not able to answer (Olvera-Vazquez et al. 2020).

\section{References}

Blanquart F, Kaltz O, Nuismer SL, Gandon S (2013) A practical guide to measuring local adaptation. Ecology Letters, 16, 1195-1205. https://doi.org/10.1111/ele.12150

Briscoe Runquist RD, Gorton AJ, Yoder JB, Deacon NJ, Grossman JJ, Kothari S, Lyons MP, Sheth SN, Tiffin P, Moeller DA (2019) Context Dependence of Local Adaptation to Abiotic and Biotic Environments: A Quantitative and Qualitative Synthesis. The American Naturalist, 195, 412431. https://doi.org/10.1086/707322

Chambers CD, Feredoes E, Muthukumaraswamy SD, Etchells PJ, Chambers CD, Feredoes E, Muthukumaraswamy SD, Etchells PJ (2014) Instead of "playing the game" it is time to change the rules: Registered Reports at <em>AIMS Neuroscience</em> and beyond. AIMS Neuroscience, 1, 417. https://doi.org/10.3934/Neuroscience.2014.1.4

Hargreaves AL, Germain RM, Bontrager M, Persi J, Angert AL (2019) Local Adaptation to Biotic Interactions: A Meta-analysis across Latitudes. The American Naturalist, 195, 395-411. https://doi.org/10.1086/707323

Hoeksema JD, Forde SE (2008) A Meta-Analysis of Factors Affecting Local Adaptation between Interacting Species. The American Naturalist, 171, 275-290. https://doi.org/10.1086/527496

Kaltz O, Shykoff JA (1998) Local adaptation in host-parasite systems. Heredity, 81, 361370. https://doi.org/10.1046/j.1365-2540.1998.00435.x

Kawecki TJ, Ebert D (2004) Conceptual issues in local adaptation. Ecology Letters, 7, 12251241. https://doi.org/10.1111/j.1461-0248.2004.00684.x

Nuismer SL, Gandon S (2008) Moving beyond Common-Garden and Transplant Designs: Insight into the Causes of Local Adaptation in Species Interactions. The American Naturalist, 171, 658668. https://doi.org/10.1086/587077

Olvera-Vazquez SG, Remoué C, Venon A, Rousselet A, Grandcolas O, Azrine M, Momont L, Galan M, Benoit L, David G, Alhmedi A, Beliën T, Alins G, Franck P, Haddioui A, Jacobsen SK, Andreev R, Simon S, Sigsgaard L, Guibert E, Tournant L, Gazel F, Mody K, Khachtib Y, Roman A, Ursu TM, Zakharov IA, Belcram H, Harry M, Roth M, Simon JC, Oram S, Ricard JM, Agnello A, Beers EH, Engelman J, Balti I, Salhi-Hannachi A, Zhang H, Tu H, Mottet C, Barrès B, Degrave A, Razmjou J, Giraud T, Falque M, Dapena E, Miñarro M, Jardillier L, Deschamps P, Jousselin E, Cornille A (2020) Large-scale geographic survey provides insights into the 


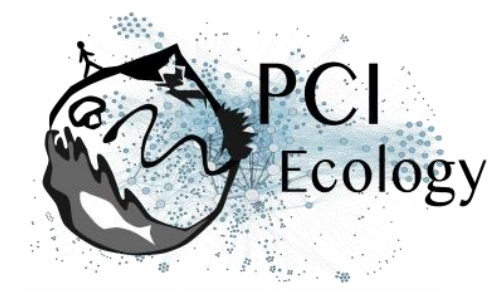

colonization history of a major aphid pest on its cultivated apple host in Europe, North America and North Africa. bioRxiv, 2020.12.11.421644. https://doi.org/10.1101/2020.12.11.421644

Olvera-Vazquez S.G., Alhmedi A., Miñarro M., Shykoff J. A., Marchadier E., Rousselet A., Remoué C., Gardet R., Degrave A. , Robert P. , Chen X., Porcher J., Giraud T., Vander-Mijnsbrugge K., Raffoux X., Falque M., Alins, G., Didelot F., Beliën T., Dapena E., Lemarquand A. and Cornille A. (2021) Experimental test for local adaptation of the rosy apple aphid (Dysaphis plantaginea) to its host (Malus domestica) and to its climate in Europe. In principle recommendation by Peer Community In Ecology. https://forgemia.inra.fr/amandine.cornille/local_adaptation_dp, ver. 4.

Parker IM, Gilbert GS (2004) The Evolutionary Ecology of Novel Plant-Pathogen Interactions. Annual Review of Ecology, Evolution, and Systematics, 675700. https://doi.org/10.1146/annurev.ecolsys.34.011802.132339

Peer Community In. (2020, January 15). Submit your preregistration to Peer Community In for peer review. https://peercommunityin.org/2020/01/15/submit-your-preregistration-to-peer-community-in-forpeer-review/

Richardson JL, Urban MC, Bolnick DI, Skelly DK (2014) Microgeographic adaptation and the spatial scale of evolution. Trends in Ecology \& Evolution, 29, 165-176. https://doi.org/10.1016/j.tree.2014.01.002

Cite this recommendation as:

Eric Petit (2021) A planned experiment on local adaptation in a host-parasite system: is adaptation to the host linked to its recent domestication?. Peer Community in Ecology, 100079. 10.24072/pci.ecology.100079

\section{Reviews}

Toggle reviews

\section{Revision round \#2}

2021-02-10

\section{Author's Reply}

Download author's reply (PDF file)Download tracked changes file

\section{Decision round \#2}

All reviewers agree upon the fact that you satisfactorily addressed their main comments and questions.

Please however consider the following additional comments before I can recommend your preprint:

- your reference list has not been updated so that many papers you cite in the revised version of your preprint cannot be found in the reference list; it seems also that some of the papers that are cited in the reference list do not correspond to citations (different years for instance) ;

- lines 150-155: please rephrase to make your argument easier to follow. The rosy apple aphid is widely distributed all across the range of its domesticated host in Eurasia, also covering the distribution of its wild contributors (M. sieversii and M. sylvestris). Your population genetic study of the aphid, though quite extensive, did not address the question of its relationships with M. sieversii. It seems thus difficult to exclude that this parasite did not follow the domestication of apple trees before they were introgressed with $\mathrm{M}$. sylvestris and other wild relatives (see Cornille et al. 2012 Plos Genet);

- line 296: do you really mean "conformed"? See also "by12"; 


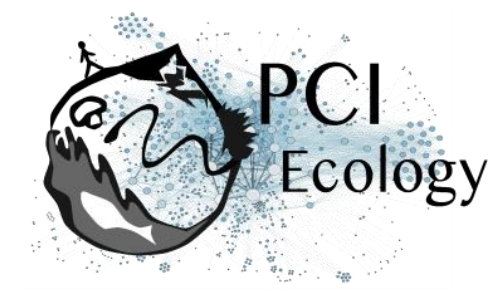

- Table 3: please make column headers correspond to the columns of the Table (3 column headers for 4 columns);

- Fig. 1: the red dot is not placed on Asturia, the green one is not close to Angers, and the blue one is in France, not in Belgium;

- Fig. 3: the legend and the figure overlap.

Eric Petit

Preprint DOI: https://forgemia.inra.fr/amandine.cornille/local_adaptation_dp

Reviewed by Alex Stemmelen, 2021-02-03 14:46

Download the review (PDF file)

\section{Reviewed by Sharon Zytynska, 2021-01-28 16:45}

I have read through the author responses to all reviewer comments, and the updated version. The authors have clearly taken consideration of all comments made and also performed preliminary tests to ensure their methods will lead to the strongest output. I have no further comments and wish them well for the experiment.

Reviewed by anonymous reviewer, 2021-01-10 11:26

Download the review (PDF file)

\section{Revision round \#1}

2020-09-29

\section{Author's Reply}

Download author's reply (PDF file)Download tracked changes file

\section{Decision round \#1}

Dear authors,

all reviewers and I agree that this preprint provides a fair report of a well designed and powerful local adaptation experiment. The reviewers however underline some weaknesses. Please try to address those as it will help you improve your experimental setup and the planned data analyses. Altogether, this will lead to a more robust experiment and stronger conclusions. In particular, the reviewers noted: (1) a lack of consistency in the way the words genotype, cultivar and variety are used; (2) a possible confounding effect of site with climatic variables; (3) that the way fitness will be measured needs further explanation; (4) that you should consider systemic apple tree responses, and the way domestication may have altered these and more specific responses to aphids; (5) misspecifications of statistical models.

I appreciate you submitted your preprint to $\mathrm{PCl}$ and I look forward to reading you revised version soon.

Preprint DOI: https://forgemia.inra.fr/amandine.cornille/local_adaptation_dp

Reviewed by Alex Stemmelen, 2020-09-17 13:35

Download the review (PDF file) 


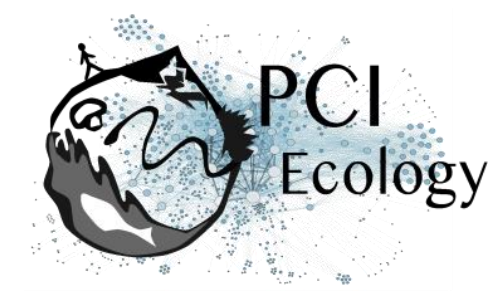

\title{
Reviewed by anonymous reviewer, 2020-09-10 06:39
}

\author{
Download the review (PDF file)
}

\section{Reviewed by Sharon Zytynska, 2020-08-26 15:58}

I have read and evaluated this pre-registration of an experiment planned for 2021 . The experimental idea is interesting and should provide sufficient data to test the hypotheses presented. There has obviously been a lot of thought put into the design of the experiment with a clear timeline for experimental setup and a clear design at the field level. I do not have any major comments to add, just a couple of points to consider for the set up and data collection. I also added these to the submitted pdf but will highlight the main points here, in case you cannot access the attached file.

I like the idea to infest different leaves of the apple trees to the nine different aphid genotypes. However, there is no mention of the potential pitfalls of using cellophane bags outside for the duration of the season. Some bags we have previously used do not stand up well to water, and so rain periods could affect the integrity of the bags. Securing the bags effectively is also important to secure the aphids inside and keep natural enemies out. Elastic tends to degrade quickly in sunlight and break while thread/wool can loosen over time. My comment is to just consider this if you haven't already.

Will you also cover the control tree leaves with cellophane bags? While this may have no impact, it is possible that any increased temperature/humidity inside the bags (small but unlikely to be zero) might impact pathogen growth leading to stress increase for the plant other than aphid infestation. Covering the leaves could also induce some plant signalling that may also influence plant responses. It is worth considering if you haven't already.

I think the counting of aphid adults and nymphs will be extremely time consuming after the first generation, so perhaps once the new offspring develop to adults it is reasonable to just count the numbers of winged vs unwinged aphids. Perhaps a small subset of replicates could be chosen to do more in depth aphid life cycle observations. With only three people per common garden, it might be worthwhile simplifying the data collection to maintain reliability.

Other minor comments: Keep consistency with what you call a cultivar versus a genotype throughout the hypotheses and figures etc Question 5, all other subheadings for hypothesis have been in bold text Question 5, Hypothesis 1 (the 1 is missing) Throughout just check you write susceptible rather than sensitive (correct in figures but I noticed two places on page 6 and Table 1)

Download the review (PDF file) 